\title{
Pushing Open Government Through Social Media
}

\author{
Christian Born \\ Heinrich Heine University Düsseldorf, Germany \\ christian.born@hhu.de \\ Christine Meschede \\ Heinrich Heine University Düsseldorf, Germany \\ christine.meschede@hhu.de
}

\begin{abstract}
E-government aims to enhance the interaction between citizens, business, and government. Recently, the term open government is increasingly used to emphasize the importance of co-creation in governmental issues. In this study, the social media activities of the municipalities of North Rhine-Westphalia, Germany, are investigated with regard to the topic "open government" as one pillar of e-government. The findings show that user interaction is mostly represented through likes and shares and rarely by comments. A topic detection of the posted content reveals that different terms are covered by the municipalities and shows that open government is getting more and more diverse in recent years. The number of posts is still increasing each year on the social media platforms Facebook and Twitter, but the topic of open government is still a peripheral phenomenon.
\end{abstract}

\section{Introduction}

Scientists, economists, and governments have investigated and developed how processes and services could be improved with the use of information and communication technologies (ICT). Terms like egovernment or government 2.0 have popped up in the literature [3]. Both terms are used to describe an enhanced cooperation between government, citizens, and business [15]. Governments are requested to change its orientation to a citizen-centered perspective [7]. Government 2.0 is further used to refer to a "more open, social, communicative, interactive and usercentered version of e-government" [27, p. 59] and includes as well activities on social media platforms. It is further expected that e-government improves the interaction with citizens and that more transparency could enhance trust and participation of citizens [2].

\author{
Agnes Mainka \\ Heinrich Heine University Düsseldorf, Germany \\ agnes.mainka@hhu.de \\ Tobias Siebenlist \\ Heinrich Heine University Düsseldorf, Germany \\ tobias.siebenlist@hhu.de
}

Governments that establish one or more social media profiles do not automatically increase eparticipation through online voting and discussions [5]. It is instead the first step to enhance their governmentto-citizens communication, collaboration, and participation online [37]. Governmental social media activities are mostly investigated for a specific purpose, e.g., communication [35]. Having a social media profile is not to be equated with being open, innovative and collaborative. In this work, we are investigating if social media profiles of governmental agencies are used to push open government. For this purpose, we conducted a case study of 397 municipalities in the federal state North-RhineWestphalia, Germany.

\section{E-government and Social Media}

In general, the term e-government is used to describe web-based services from local, state, and federal agencies [31]. It includes governmental websites, governmental social media profiles, and other governmental online services. Mostly the term is also used to refer to the use of ICT that should increase political debates and invite citizens as well businesses to actively engage in decision-making processes. However, governmental agencies that use ICT do not automatically invite businesses and citizens to collaborate actively. We can instead differentiate between different pillars of e-government [12]: (1) information dissemination, (2) communication, (3) transaction, (4) interoperability, and (5) participation. Fietkiewicz et al. [12] investigated 31 e-governments of world cities and concluded that most of the governments are not highly developed in all pillars. Egovernment mainly focuses on information dissemination. Similar results are found by Feeney and Brown [9] who investigated local governments in the US.

In this work, we are going to investigate the fifth pillar "participation" according to the social media 
presence of governmental agencies. Today, social media is used by a high number of citizens. Facebook, Twitter, and YouTube have more than 3.4 billion registered users [1], [36], [41]. Businesses are using social media profiles successfully for marketing purposes [19]. Communication via social media channels is fast and comfortable, and due to its wide distribution in the population, it can increase the participation of citizens and trust in government [13]. In research, governmental social media activities are investigated to compare activities worldwide [24] as well to scrutinize local behaviors [9], [30], [32], [33].

By definition, social media channels are communication platforms. Therefore, we assume that governmental agencies that established social media profiles use this opportunity. However, communication is not participation. We are going to investigate if social media channels are used to communicate participation opportunities in local governments actively.

Citizens are at the center of the introduction of open government. Transparency, participation, and collaboration are characteristics that they experience directly in everyday life and can thus experience an added value. To achieve this, however, they need to know about these changes and be able to participate in the introduction and implementation of individual steps. In order not to rely on a closed system, information and discussion opportunities are offered on social media channels. With these media, it is possible to reach a large number of citizens.

\section{Implementation of Open Government in Germany}

Open Government is promoting a culture of transparency, participation, and collaboration [26]. According to Young and Verhulst [40], four categories can be named where open government has an impact: improving government, empowering citizens, solving public problems and creating opportunities, like economic growth. Our focus in this work is inspired by the empowerment of citizens, having the possibility to inform themselves and to communicate with municipal or federal administrations and their fellow citizens.

Open government in Germany is in its infancy. In 2016, for example, a new law was adopted that aims at improving the development of e-government in the federal state North-Rhine-Westphalia [16]. Due to the autonomy of the federal states, no national binding law could be adopted. Nevertheless, several open data platforms have been established on the national level (govdata.de), federal level (e.g., open.nrw) and city level (e.g., offenedaten-koeln.de).
A study on the implementation of e-government in Germany has shown that $29 \%$ of the local authorities offer open administration data beside other information on their local websites [18]. Only 9\% support open data portals and $48 \%$ use at least one social media channel.

Following Weber [39], larger municipalities tend to invest more in the development of open and egovernment processes. However, the maturity of egovernment is not related to the size of a municipality. For the population, e-government services become self-evident, and if not supported by the government, other suppliers could offer such services which would lead to a loss of control by the government.

Open Government can be introduced in various ways. Thereby, an overall strategy can be adopted or proceeded in small steps that fit together. One way to change towards an open government is the use of open innovation.

The term open innovation was established by Chesbrough [4]. He refers to an innovation process that emerges in industrial production. As a primary change in the industrial environment, he describes the inclusion of external ideas. The participation of diverse stakeholders (e.g., customer, suppliers, competitors) is the central aspect of the innovation planning process. Most open innovation processes can be found in large high tech industries but as well, in a few cases, in governmental institutions and agencies [10]. Open innovation, if successfully established, leads to the development of new products and even the entrance into new markets.

Open innovation projects focus on stakeholder (especially the user) involvement and the creation of a supporting eco-system [17]. An eco-system that allows co-creation of diverse stakeholders is essential for open innovation [8]. In our case, the users are the stakeholders which refer to actual users and to potential users, e.g., those who have former been dissatisfied users. By using co-creation, different actors come together to work on a project, e.g., citizens and people from the municipal administration.

Social media channels may play an important role in open innovation. One example is knowledge crowdsourcing. To publish a current problem to the online community may help to identify potential solutions [22]. In the governmental context, the term "citizensourcing" emerged to describe the process of open innovation [9], [22]. Furthermore, the inclusion of citizens in the decision-making process is referred to as "open government" [14]. Open innovation, as well as the use of social media channels is not accepted or even implemented immediately by governmental agencies due to old structures and established routines [22]. 
In the governmental context, open innovation may also refer to open data [20]. If a government supports open data, citizens and businesses can use this data, mostly free of cost, and develop new products and services based on it. Governments further encourage people to use open data, e.g., by running hackathons or app contests [23]. This implies that governments have to ask for user participation. Therefore, we assume that the upcoming trend of open data and hackathons results in more communication on social media channels to invite potential open data users.

\section{Method}

The following research questions are investigated by a case study in North-Rhine-Westphalia, Germany:

1. How active are municipalities on social media platforms and how many reactions do they get?

2. How often and in which context do municipalities communicate topics related to open government?

\subsection{Data collection}

To answer these questions, we first had to gather data from social media activities. In our case study, we investigated 397 municipalities of North-RhineWestphalia in Germany. In Figure 1 all steps of the data collection process are presented. A list of all municipal websites was used as a starting point [29]. A crawler was used to browse the URLs of these websites and to search for links to social media profiles. In line with previous studies of governmental social media use, links to the following social media platforms were retrieved: Twitter, Facebook, YouTube, Google+, Flickr, Instagram, LinkedIn, Xing, Pinterest, Vimeo, Foursquare and Tumblr [24]. The most common social media platforms are Facebook, Twitter, and YouTube. We decided to concentrate on these three social media platforms in the following. These links were collected in a database, and an additional crawler gathered all content posted on the identified social media profiles

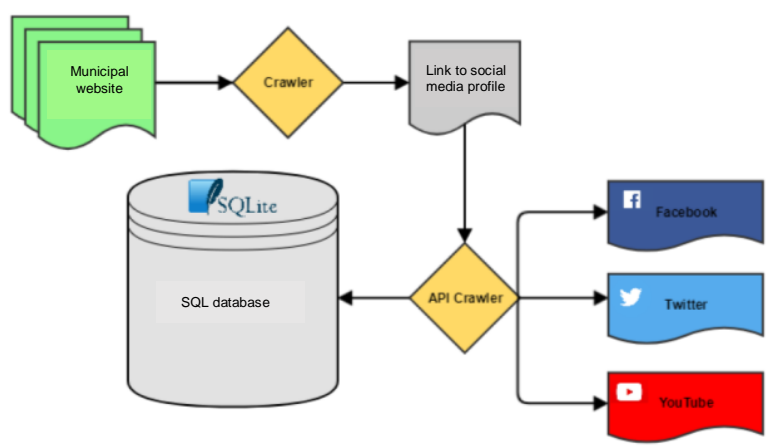

Figure 1. Social media data collection and related metadata. The links were collected at the 28th of October, 2017 and the social media content was collected between the 23rd December, 2017 and 1st January, 2018.

The data collection has some limitations. All data was gathered through the API supported by each social media platform. Accordingly, we were able to collect the content of the posts and additional metadata, e.g., likes, comments, time, and shares. On Twitter, our collection was limited to the last 3200 tweets of a user. On the other two platforms the number is not limited. For YouTube, we further included "views" as user reactions. By definition, to view a video is not a reaction but YouTube users are not as likely to "like" or to comment a video. Often, YouTube videos are shared through other social media platforms. If a user clicks on such a video teaser to watch the video, a view is counted on YouTube. Therefore, we use views as a kind of reaction.

\subsection{Descriptive data analysis}

The data investigation is split into two parts: (1) a detailed investigation of the social media activities and (2) a topic detection according to Rohrdantz et al. [34]. For the descriptive investigation, all content and metadata were identified and aggregated. Due to the limitation of the Twitter API we had to set a limit for all profiles. For better comparability, we decided to set a timely cut for all profiles. Based on the profiles that have posted more than 3200 posts we identified the oldest post and have set this date as the starting point of the investigation for all profiles. Therefore, the investigation is limited to all data posted between the 13th Mai, 2008 at 10:18:35 am and the 23rd December 2017 at 07:00:00 am.

\subsection{Topic detection}

The goal of the topic detection is to identify in which context open government is discussed on social media platforms. Initially, terms that are associated with open government were listed. Thereby, different spellings were considered. The terms were manually selected based on (1) a literature review on open and egovernment and (2) concepts identified in interviews with 13 municipalities in North-Rhine-Westphalia:
- hackathon

- hackday

- open data

- e-government

- open government

- transformation

- digitization
- $\quad$ administrative

data

- transparency

- online citizen participation

- citizen

participation 
- $\quad$ open government pact

- open knowledge

- transparency law

- freedom of information
- participation

- e-participation

- more democracy

- vote manager

- election portal

- de-mail

For the context investigation all textual data was considered: On Twitter the tweet text; on Facebook the post text and if available the description; on YouTube the title, the description, and the tags. All text was adjusted, normalized and transformed into lowercase letters. In the next step, the terms were retrieved in the data collection. For each match, 25 words before and after the term were extracted for the further investigation. The extracted data was tokenized with the use of SpaCy (https://spacy.io/) to reduce the complexity of the data [21]. Besides, all punctuation marks and stop words were deleted. The stop word list includes the names of the cities and municipalities of North-Rhine-Westphalia because they occurred very often.

Based on this corpus we performed a topic detection with Latent Dirichlet Allocation (LDA) as a method with the software MALLET [25]. With MALLET, 20 term clusters were identified. Each cluster aggregates terms that have a high probability to occur in this context. The most frequent clusters with their terms are shown in Table 1.

Table 1. Term clusters of the ten most frequent topics related to open government.

\begin{tabular}{|c|c|c|}
\hline$\#$ & Terms & Count \\
\hline 1 & $\begin{array}{l}\text { citizen participation, city, citizen, } \\
\text { frame, female citizens, transparency, } \\
\text { giving, household, administration, } \\
\text { opportunity, inform, interest, mayor, } \\
\text { standing, ideas, invite, discuss, } \\
\text { participate, heartfelt, information }\end{array}$ & 201 \\
\hline 2 & $\begin{array}{l}\text { citizen participation, find, suggestions, } \\
\text { introduce, start, event, frame, } \\
\text { downtown, remodeling, citizen, } \\
\text { monday, redesign, interest, public, old, } \\
\text { july, female, results, represent, ideas }\end{array}$ & 168 \\
\hline 3 & $\begin{array}{l}\text { opendata, opendatamoers, new, info, } \\
\text { opendatabonn, thanks, portal, online, } \\
\text { moers_de, small, transparency, give, } \\
\text { elmarburke, opennrw, hackday, care, } \\
\text { opendata portal, anked, getting, future } \\
\text { forum }\end{array}$ & 155 \\
\hline
\end{tabular}

hackday, open, data, data, city, city

hall, find, give, jobs, lower rhine,

4 order, code, march, info, great,

workshop, free, april, city

administration, develop

digitalization, theme, lecture, topics, opportunities, internet, event,

5 economy, digital, circle, offers, egovernment, vhs, giving, commune, discuss, industry, schools, steinfurt, november

app, election results, votemanager, voting portal, free, assignment, results,

6 sunday, votemanager app, smartphone, live, up-to-date, let, track, give, retrieve, search, website, link, android

digitization, business, economy, change, commerce, theme, innovation,

7 business promotion, energy, digital, breakfast, center, stand, nrw, digital, north rhine-westphalia, philipp, fast, expert, city

e-government, college, project, rheinwaal, city, open, school, data,

8 adolfinum, arndt, rejoicing, claus, demail-address, students, binding, common, schulerw, gymnasium, class, dispose

transparency, citizen participation, communities, goal, saying, energy

9 turnaround, information, set, theme, openness, create, important, together, show, energy, wind, find, public, multiple, announce

participation, city, project, promote, children, democracy, mayor, frame,

10 project, support, democratic, youthful, region, innovative, digital, aging, actions, media literacy, cultural, events

\section{Results}

In the following, the results related to our two research questions will be presented. Both will be compared and discussed in the subsequent chapter.

\subsection{Social media activity}

Out of the 397 investigated municipal websites, 162 have at least one social media profile on Facebook (147 profiles), Twitter (74 profiles), or YouTube (51 
profiles). We investigated the posts from Mai 2008 to December 2017. The number of posted content increased each year (Figure 2). In total, we counted 326,812 posts. Most content is posted on Facebook with $63,71 \%$ of the posts, followed by Twitter with $35,65 \%$ posts and YouTube with $0.64 \%$ posts. The small number of YouTube posts is not surprising since producing and posting a video costs more effort than to type a short text on Twitter. The high number of Facebook posts in comparison to the posted tweets is further related to the higher number of investigated Facebook profiles. Figure 2 presents the average number of posts per social media account for each year investigated. On average the most posts are counted on Twitter. This is as well not surprising since microblogging posts are short and quickly created. Further, it should be noticed that the number of accounts per year has increased as well but was not taken into account in order to simplify the presentation.

The number of posts in 2008 do only present seven months in that year but will be further considered in the content analysis, and is therefore presented here as well.

Beside the number of posts, it is of interest how many reactions the municipalities got. The reactions of social media posts can be counted by the number of comments, likes, dislikes, shares, and views. As shown in Figure 3, the number of reactions increases yearly. The most reactions are views and likes. Due to the high number of views, we inserted a secondary axis in Figure 3 for a better representation. The reactions are calculated as the average number per social media account for each year. Users of social media platforms do rarely comment on Facebook posts, YouTube

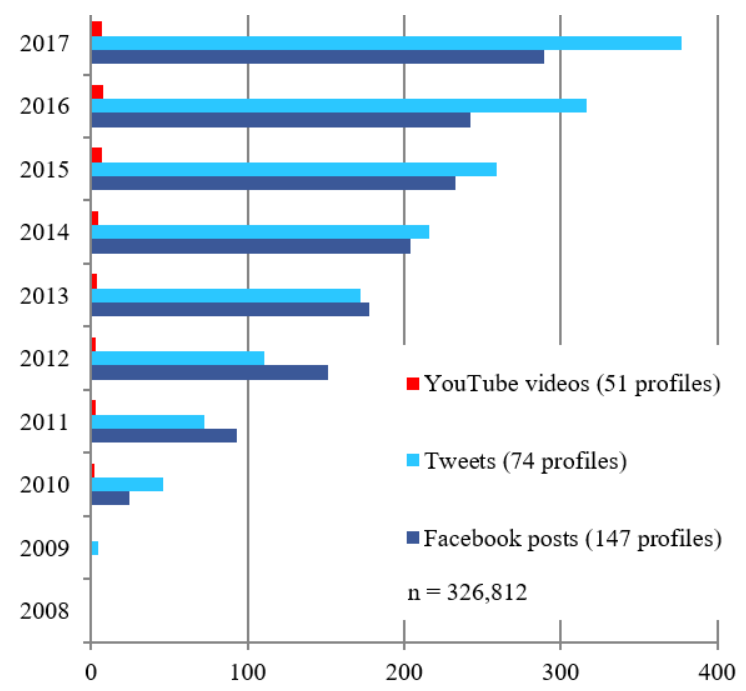

Figure 2. Number of social media posts per year and average per municipal social media profile

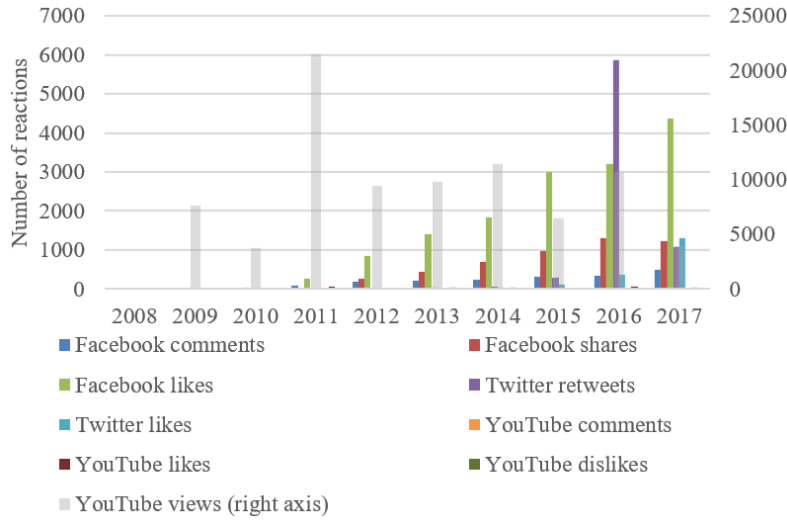

Figure 3. Average number of reactions per social media profile and year

videos or tweets on Twitter.

In 2011, we see a peak according to the number of views of YouTube videos, and in 2016 a peak of Twitter retweets. The YouTube peak is the result of a video of a philharmonic concert which has more than 600,000 views. The number of Facebook likes is continuously increasing each year. In general, the interactions on YouTube show varying numbers and do not increase yearly as on both other social media platforms.

The three social media platforms offer different possibilities for posts. On YouTube, only videos are uploaded whereas on Facebook, and Twitter text, pictures, videos, and links may be included in one post. Taking a look at the types of posted media on Facebook and Twitter, most of the posts are text or text including links to other websites. Pictures are posted in $11.72 \%$ of the investigated tweets and $45.23 \%$ of the investigated Facebook posts. Videos are included in $0.21 \%$ of tweets and $2.57 \%$ of Facebook posts of the corpus. Facebook and Twitter are further used to share videos that are uploaded on YouTube. This possibility and the small numbers of shared videos illustrate the lower activities on YouTube.

\subsection{Topic detection with regard to open government}

In the following, the content of municipal social media profiles will be investigated. The goal is to identify whether open government is a topic that is communicated through official channels on Facebook, Twitter, and YouTube.

Compared to the numbers of posts in Figure 2, the number of posts that are related to open government is small. In total 1,288 posts out of 326,812 can be dedicated to this topic. Looking at the total numbers of posts on social media profiles, we see that the most posts are identified on Facebook. Figure 4 shows the 


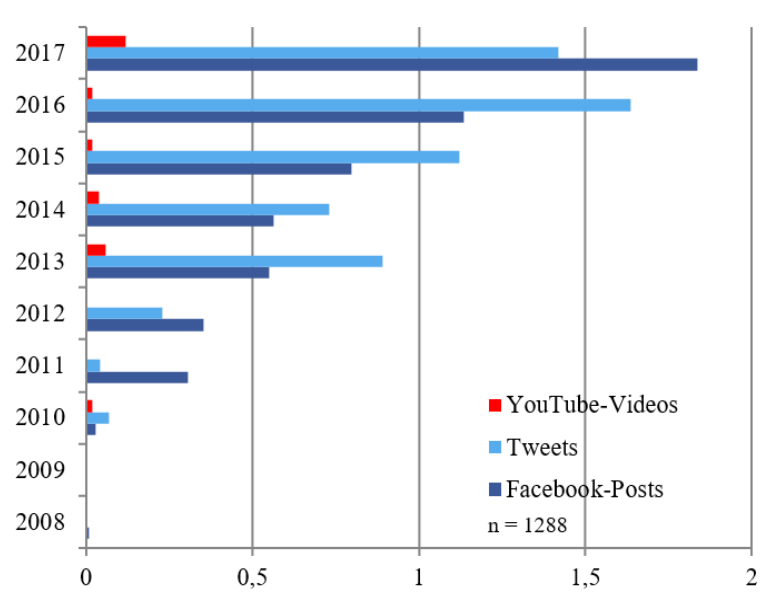

Figure 4. Posts with the topic open government as average number of social media profiles presented per year.

average numbers of posts per social media channel for each investigated year. Again, the most posts related to the topic "open government" can be found on Facebook. On Facebook and Twitter, we see a growing number of posts each year. The number of YouTube videos is varying in a yearly comparison.

Based on the 1,288 posts, we identified 20 term clusters that are related to the topic "open government". The ten most frequent term clusters are presented in Table 1. All terms that are listed in the same topic have a high probability to occur jointly. The terms are translated from German into English.

The first topic represents the topic of citizen participation. The occurrence of the terms "inform," "ideas," "invite," "household," and "discuss" indicate that this topic is often related to inviting citizens to discuss the municipalities' household issues.

The second topic as well includes the term "citizen participation", but frequently occurs together with another cluster of terms. The evidence of the terms "redesign" and "downtown" suggests that this topic is referred to urban planning.

Topic three and four represent terms related to open data and hackathons. The third merges open data portals and the most common actors (the cities Bonn and Moers presented by "opendatabonn" and "opendatamoers"). The fourth topic includes the term "hackday" and "workshop" as well as the months "march" and "april" which indicates that posts of this topic are related to events that took place at this time.

The next cluster is related to terms that are referred to digitization and e-government in general. The other terms, e.g., "topics" and "lecture," indicate that this cluster is related to lectures and events that inform and discuss e-government and digitization.
The terms in cluster six refer to elections and apps that have supported the citizens to vote or to decide whom to vote for. For example, the "votemanager" is an app that offers both possibilities.

Cluster seven includes terms that refer to the changing economy due to the increase of digitization. Cluster eight is related to the topic of e-government which is discussed or developed together with school classes. Here the terms "school," "adolfinum," and "students" stand out.

The ninth cluster again is related to citizen participation but now occurs in the context of energy and transparency. This may be related to discussions and developments concerning the turnaround in energy policy and consumption.

Finally, the tenth cluster is related to children and media literacy. Probably, the encouragement of children according to participation and media literacy was promoted.

In general, frequent terms in this investigation are citizen and participation. This demonstrates that these terms occur in posts of the municipalities' social media profiles. This could be an indicator that open government is represented by these terms. In conclusion, however, this cannot be stated without further consideration. It was not possible to identify one overriding topic for all of the 20 term clusters, but the ten most frequent topics were described here. In the following, these clusters will be further analyzed.

Looking at the occurrence of the identified topics, Figure 5 shows the temporal distribution. It is striking that posts in 2008 and 2009 could not be assigned to the topic "open government." In 2010, the most frequent topic was topic two which is related to citizen participation in urban planning. In the following year, topic one is prevalent. Similar to topic two, citizen participation is emphasized. After 2011, these topics are not dominating anymore. This does not mean that the number of posts that refer to topic one and two has

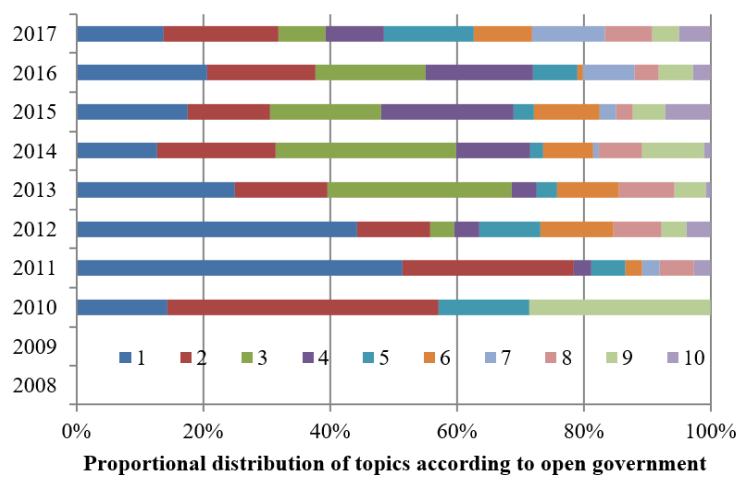

Figure 5. Proportional distribution of topics related to open government per year. 
decreased, instead the number of posts with further topics of open government has increased. Accordingly, in the years 2013 and 2014, topic 4 (hackday) is dominating. In 2015 and 2016, topic 5 (lectures) gets more attention in municipal social media activities.

Finally, we will take into account the number of reactions according to social media posts that are related to open government. Since no posts were found in 2008 and 2009, these two years are not further presented. As shown in Figure 6, the highest number of reactions are YouTube views. As shown in Figure 3, we had to add a secondary axis for a better representation. Views are a weakened reaction as a user only needs to click to play the video. The number of views varies between 2010 and 2017. This indicates that views are highly related to the content of the videos. In average, the second most reaction is found for Facebook posts. Likes and other clickable reactions (e.g., dislike, smile, love) are the most common reactions. Facebook shares that ask for a user's additional comment are less frequent. In comparison, posts related to open government lead only to very few likes and retweets on Twitter.

Comments are rare on each social media platform. Users mostly read, view and eventually click a like button. Therefore, it is not surprising that the videos in the corpus are less commented and similarly the numbers of commented posts related to open government are low.

Similar to the general corpus, the social media posts related to open government on Facebook and Twitter often include pictures. Forty-six percent of the Facebook posts and $12 \%$ of the Tweets show a picture. Videos are less represented with $0.22 \%$ on Twitter and $1.71 \%$ on Facebook. Nearly $7 \%$ of the Facebook posts are event invitations.

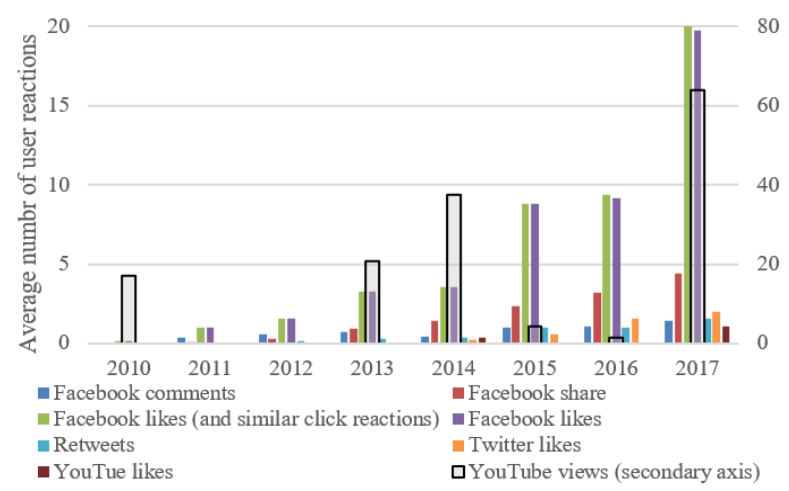

Figure 6. Average number of user reactions for social media posts related to the topic open government.

\section{Discussion}

The investigation of official social media profiles of municipalities in North-Rhine-Westphalia has shown that the number of activities on these platforms is continuously increasing. This can be interpreted as a positive development of municipalities towards egovernment. The use of social media enables new forms of accessibility and communication for governments. Besides, municipalities that are skeptical towards online communication through platforms like Facebook, Twitter, and YouTube have now the chance to learn from other governmental agencies that are already social media users. Probably, strong user stories may encourage other municipalities to join this movement.

In contrast, the number of comments and actual interactions is quite low. To communicate with citizens and businesses is one essential pillar of successful egovernment. The investigated municipalities do not exploit the potential that is offered through social media. However, topics related to open government occur in posts of municipal governments since 2010 and the number of those posts is increasing. It should be further analyzed if the low number of comments is owed by the general wording or formulation of the posts or due to the posted topics. Only discussions which are presented by comments on social media portals may help to source for citizens' knowledge. Likes, views or shares are not comparable to a real dialog.

However, it should be considered that many contents on social media sites are rarely commented [6]. Therefore, to reach many people online does not result in more online participation. Furthermore, the user groups of Facebook and Twitter are not representative of the whole population [28].

To extend the attention on social media platforms, different types of media should be posted like pictures and videos as well as invitations to events [38]. Nearly half of the Facebook posts include different media (45\% pictures and $2.5 \%$ videos). Merely $12 \%$ of all investigated Facebook posts consist only of text. Comparing the corpus with the posts related to open government, no difference in the posting behavior can be identified. Following de Vries et al. [38] the inclusion of videos and events is the best method to increase interactions. Accordingly, municipalities could try to reach higher numbers of comments by posting more videos and invite the users to local events. Interestingly, the identified topics related to open government refer to events that took place mostly offline, e.g., hackathons, workshops, or lectures, but online events are posted rarely. 
Based on our research using the methodology presented, we can say that the topic of open government is not very popular, since only $0.4 \%$ of all identified posts could be assigned to this topic. Nevertheless, a yearly increase in the number of posts of this topic is recorded. It should be noticed that the topic is not increasing in popularity in all municipalities. A more in-depth look into the data reveals that only a few municipalities make the most significant part of the pie in this topic distribution.

Regarding the term clusters, it becomes evident that citizen participation is the most common term in the investigation of open government posts. The aspect of citizen participation occurs in different contexts. It could be identified together with urban planning, city development, and household. This reveals that citizens are included in the planning process of the cities. In the recent years, the number of posts related to open data increased. Cities tend to open up open data platforms and invite citizens to hackathons to make use of this efforts [14]. In 2017, a decline of the open data topic is evident. This may be caused by the decrease of the importance of this topic, or this may be since some hackathons and open data platforms have their own social media profiles which have not been considered in this investigation. Also, in 2017 we can identify the most diversified topics related to open government. This reflects that topics around open government has spread and do not only focus on urban planning or hackathons. Therefore, users on social media platforms (probably citizens) get informed about diverse topics related to open government and may interact through this channels if they like.

\section{Conclusion}

In this study, we investigated the social media profiles of municipalities of North-Rhine-Westphalia, Germany, regarding the activities and user reactions in general and concerning the topic of open government. It is evident that the number of posts and reactions is increasing yearly. Only the number of YouTube videos per year is varying. We noticed that the number of comments is not growing in the same manner as the number of likes and shares. We identified most reactions and posts on Facebook, which is due to the high popularity of this social media channel in Germany. In other nations, this may vary in favor of other popular social media platforms.

With the use of LDA, 20 topics were detected that are related to open government. The ten most occurring were analyzed in this paper. The topic detection has revealed that open government is expanding to different themes. It started with participating in urban planning and hackathons and is now as well related to lectures and media literacy. The investigation of the topics has highlighted the topics that are of importance in the local region. Many of the terms are assigned to the local community, like protagonists of the open government movement or events that took place. Topic detection is a method that can help to identify and represent the evolution of topics over years as presented in this paper. Also, a more in-depth analysis of social media data is of interest. Data mining techniques can provide further insights from this data. This can contribute to understand which municipalities publish content on the topic of open government and discussed by and with citizens. Furthermore, opinions on individual topics can be collected through content analysis. A stronger focus should be placed on the metadata. These provide information about the interaction with the content and can be used for further analysis in connection with the content and the comments. Such an evaluation can be used to obtain further critical data on the interaction of municipalities with citizens and citizens among themselves.

In further research it could be interesting to investigate the reactions according to the most common topics and if some topics cause more user participation. Further comparison of different nations instead of investigating only one local community could help to understand user reactions on social media platforms or compare the evolution of open government in different places of the world.

\section{References}

[1] "Aktuelle Nutzerzahlen: Facebook, Instagram, WhatsApp, Messenger, Groups, ....," 2017. [Online]. Available: https://allfacebook.de/toll/state-of-facebook.

[2] J. C. Bertot, P. T. Jaeger, and J. M. Grimes, "Using ICTs to create a culture of transparency: E-government and social media as openness and anti-corruption tools for societies," Gov. Inf. Q., vol. 27, no. 3, pp. 264-271, Jul. 2010.

[3] E. Bonsón, L. Torres, S. Royo, and F. Flores, "Local egovernment 2.0: Social media and corporate transparency in municipalities," Gov. Inf. Q., vol. 29, no. 2, pp. 123-132, Apr. 2012.

[4] H. Chesbrough, "Open innovation: a new paradigm for understanding industrial innovation," Open Innov. Res. a new Paradig., vol. 400, pp. 0-19, 2006.

[5] D. Coursey and D. F. Norris, "Models of E-Government: Are They Correct? An Empirical Assessment," Public Adm. Rev., vol. 68, no. 3, pp. 523-536, May 2008.

[6] R. Effing, J. Van Hillegersberg, and T. Huibers, "Social media and political participation: are Facebook, Twitter and YouTube democratizing our political systems?," in 
International conference on electronic participation, 2011, pp. 25-35.

[7] W. D. Eggers, Government 2.0: Using Technology to Improve Education, Cut Red Tape, Reduce Gridlock, and Enhance Democracy. Plymouth, UK: Rowman \& Littlefield Publishers, 2005.

[8] European Commission, "Open Innovation, Open Science, Open to the World. A Vision for Europe," Luxembourg, LUX, 2016.

[9] M. K. Feeney and A. Brown, "Are small cities online? Content, ranking, and variation of U.S. municipal websites," Gov. Inf. Q., vol. 34, no. 1, pp. 62-74, Jan. 2017.

[10] J. Feller, P. Finnegan, and O. Nilsson, "Open innovation and public administration: Transformational typologies and business model impacts," Eur. J. Inf. Syst., vol. 20, p. 358374., 2011.

[11] T. Felin and T. R. Zenger, "Closed or open innovation? Problem solving and the governance choice," Res. Policy, vol. 43, no. 5, pp. 914-925, Jun. 2014.

[12] K. J. Fietkiewicz, A. Mainka, and W. G. Stock, "eGovernment in cities of the knowledge society. An empirical investigation of Smart Cities' governmental websites," Gov. Inf. Q., vol. 34, no. 1, 2017.

[13] R. Gabriel and H.-P. Röhrs, "Social Media Anwendungen beim Staat," in Social Media, R. Gabriel and H.-P. Röhrs, Eds. Berlin, Heidelberg: Springer Berlin Heidelberg, 2017, pp. 91-121.

[14] T. M. Harrison, G. B. Burke, M. Cook, A. Cresswell, and J. Hrdinová, "Open government and e-government: Democratic challenges from a public value perspective," in 12th Annual International Conference on Digital Government Research, 2011, pp. 245-253.

[15] S. Hartmann, A. Mainka, and I. Peters, "Government activities in social media. An empirical investigation of eGovernment in informational world cities," in Proceedings of CeDEM the International Conference for E-Democracy and Open Government, 2013, pp. 173-186.

[16] S. Hartmann, A. Mainka, and W. G. Stock, "Innovation contests: How to engage citizens in solving urban problems?," in Enhancing Knowledge Discovery and Innovation in the Digital Age, W. D. Lytras, L. Daniela, and A. Visvizi, Eds. Hershey, PA: IGI Global, 2018, pp. 254 273.

[17] M. Henkel, A. Ilhan, A. Mainka, and W. G. Stock, "Case studies on open innovation in libraries," Proc. Assoc. Inf. Sci. Technol., vol. 54, no. 1, 2017.

[18] R. Heuermann, S. Krebs, C. D. Kohl, C. Jürgens, J. Bizer, and M. Golibrzuch, "Digitalisierung auf Landesebene," in Digitalisierung in Bund, Ländern und
Gemeinden, Berlin, Heidelberg: Springer Berlin Heidelberg, 2018, pp. 99-136.

[19] A. M. Kaplan and M. Haenlein, "Users of the world, unite! The challenges and opportunities of social media," Bus. Horiz., vol. 53, no. 1, pp. 59-68, Jan. 2010.

[20] M. Klang and J. Nolin, "To inform or to interact, that is the question: the role of freedom of information in social media policies. In: (Ed.), : (pp. 11-28).," in Information Science and Social Media: Proceedings of the International Conference Information Science and Social Media ISSOME 2011, August 24-26, 2011, pp. 11-28.

[21] M. Liebeck, K. Esau, and S. Conrad, “Text Mining für Online-Partizipationsverfahren: Die Notwendigkeit einer maschinell unterstützten Auswertung," HMD Prax. der Wirtschaftsinformatik, vol. 54, no. 4, pp. 544-562, Aug. 2017.

[22] E. Loukis, Y. Charalabidis, and A. Androutsopoulou, "Promoting open innovation in the public sector through social media monitoring," Gov. Inf. Q., vol. 34 , no. 1, pp. 99109, Jan. 2017.

[23] A. Mainka, S. Hartmann, C. Meschede, and W. G. Stock, "Open government: Transforming data into valueadded city services," in Citizen's right to the digital city: Urban interfaces, activism, and placemaking, M. Foth, M. Brynskov, and T. Ojala, Eds. Singapore, SG: Springer, 2015, pp. 199-214.

[24] A. Mainka, S. Hartmann, W. G. Stock, and I. Peters, "Government and Social Media: A Case Study of 31 Informational World Cities," in 47th Hawaii International Conference on System Sciences, 2014, pp. 1715-1724.

[25] A. McCallum, "MALLET: A Machine Learning for Language Toolkit.," 2002. [Online]. Available: http://mallet.cs.umass.edu.

[26] P. McDermott, "Building open government," Government Information Quarterly 27, 4 (oct 2010), pp. 401-413, 2010.

[27] A. J. Meijer, B. Koops, W. Pieterson, S. Overman, and S. Tije, "Government 2 . 0 : Key Challenges to Its Realization Utrecht School of Governance in the Netherlands . Scientific Council for Government Policy in the Netherlands .," vol. 10, no. 1, pp. 59-69, 2012.

[28] J. Mellon and C. Prosser, "Twitter and Facebook are not representative of the general population: Political attitudes and demographics of British social media users," Res. Polit., vol. 4, no. 3, p. 205316801772000 , Jul. 2017.

[29] MHKBG, "Kreise, Städte und Gemeinden in NRW." [Online]. Available: https://www.mhkbg.nrw/kommunales/AdressenKommunen/index.php. 
[30] G. H. M. Oliveira and E. W. Welch, "Social media use in local government: Linkage of technology, task, and organizational context," Gov. Inf. Q., vol. 30, no. 4, pp. 397405, Oct. 2013.

[31] S. C. J. Palvia and S. S. Sharma, "E-government and egovernance: Definitions/domain framework and status around the world," in International Conference on Egovernance, 2007, pp. 1-12.

[32] C. G. Reddick, A. T. Chatfield, and A. Ojo, "A social media text analytics framework for double-loop learning for citizen-centric public services: A case study of a local government Facebook use," Gov. Inf. Q., vol. 34, no. 1, pp. 110-125, Jan. 2017.

[33] C. G. Reddick and D. F. Norris, "Social media adoption at the American grass roots: Web 2.0 or 1.5?," Gov. Inf. Q., vol. 30, no. 4, pp. 498-507, Oct. 2013.

[34] C. Rohrdantz, A. Hautli, T. Mayer, M. Butt, D. A. Keim, and F. Plank, "Towards tracking semantic change by visual analytics," in Proceedings of the 49th Annual Meeting of the Association for Computational Linguistics: Human

Language Technologies: Short Papers, 2011, pp. 305-310.

[35] D. Skirbunt, T., \& Martinez, L., \& Meskell, "Government outreach to the U.S. Spanish-speaking community uses social media," in Proceedings of the 10th
Annual International Conference on Digital Government Research: Social Networks: Making Connections between Citizens, Data and Government, 2009, pp. 16-18.

[36] Statista, "Number of monthly active Twitter users worldwide from 1st quarter 2010 to 4th quarter 2017," 2017. [Online]. Available:

https://www.statista.com/statistics/282087/number-ofmonthly-active-twitter-users/.

[37] United Nations, E-Government Survey 2010. 2010.

[38] L. de Vries, S. Gensler, and P. S. H. Leeflang, "Popularity of brand posts on brand fan pages: An investigation of the effects of social media marketing," $J$. Interact. Mark., vol. 26, no. 2, pp. 83-91, May 2012.

[39] M. Weber, "Stand des e-Government in Deutschland," in Wirkungen von E-Government, J. Stember, W.

Eixelsberger, and A. Spichinger, Eds. Wiesbaden, DE: Springer Fachmedien Wiesbaden GmbH, 2018, pp. 159-180.

[40] A. Young and S. Verhulst, "The global impact of open data: Key findings from detailed case studies around the world (First edition ed.)". O'Reilly, Sebastopol, CA, 2016.

[41] YouTube, "YouTube in Zahlen," 2017. [Online]. Available: https://www.youtube.com/intl/de/yt/about/press. 